\title{
GOVERNANÇA DA RESERVA DA BIOSFERA DO CINTURÃO VERDE DA CIDADE DE SÃO PAULO
}

\author{
Prof. Dr. Wagner Costa Ribeiro \\ Pesquisador CNPq \\ Instituto de Estudos Avançados e Departamento de Geografia da Universidade de São Paulo \\ Av. Prof. Lineu Prestes, 338 - CEP 05.508-900 São Paulo (SP), Brasil \\ Tel: (011) 3091-3769 =wribeiro@usp.br
}

\begin{abstract}
RESUMO
Trata-se de analisar a gestão da Reserva da Biosfera do Cinturão Verde da Cidade de São Paulo, Patrimônio da Humanidade e parte do Programa O Homem e a Biosfera, da UNESCO, a partir da consideração de dois níveis de gestão: internacional, por meio da UNESCO, e regional, por meio da Secretaria Estadual de Meio Ambiente do Estado de São Paulo. Para tal, discute-se o que é governança, definida como a reunião de diversos sujeitos em um foro legítimo e acolhido pela estrutura de decisão do Estado, para averiguar como ela se desenvolve na reserva em questão. O autor baseou-se na documentação sobre a criação e institucionalização da reserva e em entrevistas com técnicos responsáveis pela sua gestão.
\end{abstract}

Palavras-Chave: governança, UNESCO, Reserva da Biosfera, São Paulo, políticas públicas.

\begin{abstract}
They are examining the management of the Biosphere Reserve of the Green Belt city of Sao Paulo, Heritage of Humanity and the Man and the Biosphere Program, UNESCO, from the consideration of two levels of management: international, through UNESCO, and regional levels, through the State Department of Environment of the State of Sao Paulo. To this end, discussions on whether what is governance, defined as the meeting of various subjects in a legitimate forum and structure for a decision upheld by the state, to investigate how it develops in the reserve in question. The author was based on the documentation on the establishment and institutionalization of the reserve and on interviews with experts responsible for their management.
\end{abstract}

Key words: governance, UNESCO, Biosphere Reserve, São Paulo, public policies

\section{RÉSUMÉ}

Cette article examinent la gestion de la Réserve de Biosphère de la Ceinture Verte de la Ville de Sao Paulo, Patrimoine de l'Humanité et du Programme de l'Homme et la Biosphère, l'UNESCO, sur la considération de deux niveaux de gestion: international, à travers l'UNESCO, et au niveau régional, par le biais le Département d'Etat de l'Environnement de l'Etat de Sao Paulo. À cette fin, des discussions à savoir si ce que la gouvernance, définie comme la réunion de divers sujets dans un forum légitime et la structure d'une décision confirmée par l'Etat, pour étudier comment elle se développe dans la réserve en question. L'auteur a été basé sur la documentation relative à l'établissement et l'institutionnalisation de la réserve et sur des entretiens avec des experts chargés de leur gestion.

Mot Clés: la gouvernance, l’UNESCO, la Réserve de biosphère, São Paulo, les politiques publiques

\section{Introdução}

Organização social associada às causas ambientais resulta em novas áreas naturais protegidas. Pelo menos foi o que ocorreu na Região Metropolitana de São Paulo ${ }^{1}$. Entretanto, nem sempre a criação de uma reserva implica na continuidade do movimento social.

A instalação da Reserva da Biosfera do Cinturão Verde da Cidade de São Paulo decorreu de um amplo processo de participação e mobilização sociais. Dele resultou um abaixo-assinado, que chegou a 150.000 assinaturas em 1991. O motivo que gerou tamanha articulação de pessoas foi a decisão de construir o Rodoanel Metropolitano, que cortaria a reserva de Mata Atlântica, um dos mananciais da Região Metropolitana, tornando-se um vetor de sua devastação.

Desse modo, em 9 de junho de 1994 foi criada a Reserva da Biosfera do Cinturão Verde da Cidade de São Paulo, que possui uma área de 1611710 ha, envolve 73 municípios e protege dois biomas, a Mata Atlântica e o Cerrado (figura 1 e tabela 1). Antes disso, porém, em outubro de 1993, fora declarada Patrimônio Comum da Humanidade e integrada ao Programa O Homem e a Biosfera, da Organização 
das Nações Unidas para Educação, Ciência e Cultura - UNESCO. A associação com a UNESCO garante um caráter internacional a essa reserva, ainda que formal.

A reunião de diversas instâncias de poder, no caso internacional e estadual, exige uma revisão das estruturas de gestão do patrimônio natural. Muitas vezes, ela impõe a participação social, que é associada à boa governança dos conflitos socioambientais.

Esse texto discute o tema da governança em uma perspectiva conceitual. Depois, analisa a ação de órgãos internacionais e estaduais sobre a Reserva da Biosfera do Cinturão Verde da Cidade de São Paulo, a começar pela UNESCO, e, depois, pela Secretaria de Estado de Meio Ambiente do Estado de São Paulo. Por fim, apresenta o Conselho Gestor da Reserva da Biosfera do Cinturão Verde da Cidade de São Paulo. Em sua construção foram utilizadas fontes secundárias bibliográficas e material disponível em órgãos governamentais, além de entrevistas junto a técnicos da Secretaria Estadual do Meio Ambiente pelo autor.

Pode-se dizer que apesar da Reserva da Biosfera do Cinturão Verde da Cidade de São Paulo ser resultado de importante mobilização social, a estrutura de gestão edificada após sua criação afastou os movimentos sociais, além de dar-lhe apenas caráter consultivo. Nesses termos, a governança da Reserva da Biosfera do Cinturão Verde da Cidade de São Paulo está longe de uma real participação social.

\section{A governança}

O tema da governança é recente no debate sobre as questões ambientais (Kaneie e Haas, 2004). Ele pode ser analisado em diferentes escalas, como a internacional, a nacional, a regional e a local ${ }^{2}$.

A ordem ambiental internacional estabelece normas que interferem nas demais escalas. Um país membro que ratifica um acordo internacional deve rever seus instrumentos jurídicos e de ação pública internos. Alegislação nacional e até mesmo regional deve ser ajustada aos termos aceitos internacionalmente. Nesse momento, a governança ambiental pode ser evocada nas escalas nacional e regional, mas ela está relacionada à esfera internacional.

Não existe uma hierarquia de escalas. Ao contrário, é preciso admitir que elas se articulam, se complementam, embora possam também contrapor interesses e impor visões desde a escala internacional alheias aos anseios locais e até mesmo aos nacionais.

O debate que surge na aplicação de acordos internacionais na esfera nacional e regional deve ser objeto de investigação. É preciso conhecer quem ganha e quem perde nos países e nas regiões com a implementação de acordos transnacionais, mesmo quando se contesta a governança (O’Brian, 2000).

Abordar a governança em escala internacional remete necessariamente a uma análise do sistema internacional. Entre o diverso leque de teorias oferecido para entender as relações internacionais atualmente podem-se destacar interpretações que retomam a importância do território (Mello, 1999), e outras, de caráter idealista, que buscam uma dimensão multilateral na gestão planetária.

Uma das teorias mais aceitas é a da predominância de uma superpotência, que seria capaz de afirmar sua força e interesses aos demais países diante de sua capacidade armamentista. Apesar do elevado desequilíbrio militar entre países, a superpotência, os Estados Unidos, não consegue impor sua visão sobre os demais no que se refere à gestão dos recursos naturais do planeta, situação agravada pela grave crise financeira que se instalou no país no início do século XXI. Porém, mesmo antes da crise já se notavam situações nas quais a superpotência mostrava menos influência. O Protocolo de Kyoto é um exemplo. A ausência da principal potência militar na época em que entrou em vigor não impediu seu funcionamento.

Mas também é preciso ter em mente a intenção de se construir um sistema internacional mais aberto ao diálogo, no qual prevaleça o entendimento frente ao conflito. Essa é uma das possibilidades para entender a governança internacional. A importância da opinião pública e da imprensa cresce sobremaneira, mesmo quando se sabe que a divulgação de imagens de conflitos não é aleatória e desempenha função importante na difusão de versões de guerras para a população. 


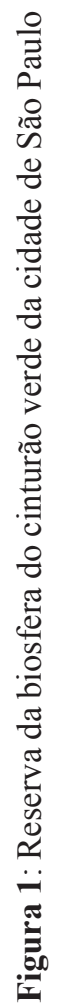

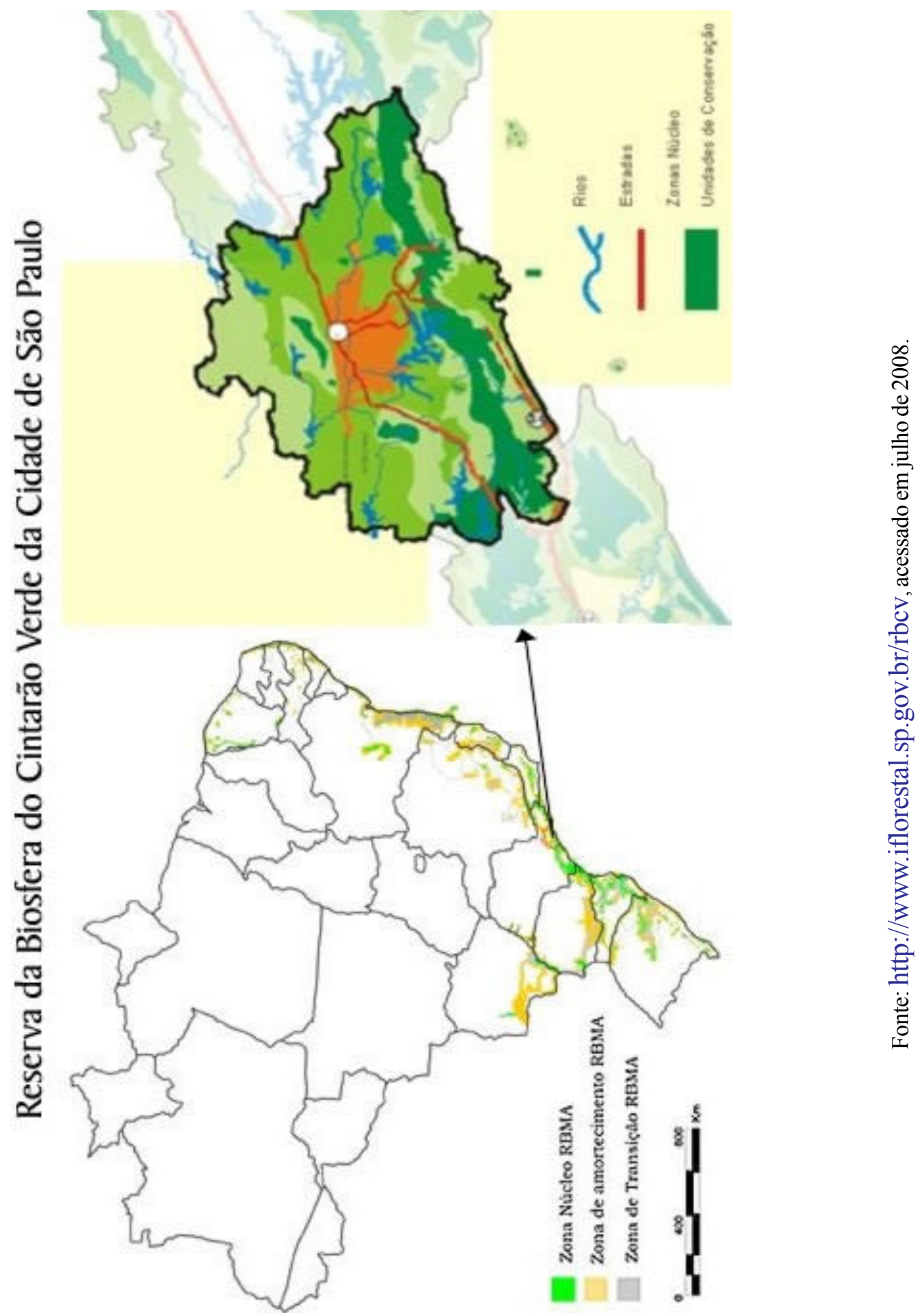


Tabela 1: Áreas protegidas e unidades de conservação da reserva da biosfera do cinturão verde de São Paulo

\begin{tabular}{|c|c|c|c|c|}
\hline MUNICIPIO & TIPO DE UNIDADE & NOME & LEGISLAÇĀO & RESPONSÁVEL \\
\hline ATIBAIA & Área de Proteção Ambiental & Bairro da Usina & Lei 5.280 , de 04/09/86 & SMA \\
\hline ATIBAIA & Área Natural Tombada & Serra de Atibaia & Lei 5.280 , de 04/09/86 & CONDEPHAAT \\
\hline BARUERI & Área de Proteção Ambiental & Varzea do Tiete & Lei 5.598 , de 06/02/87 & SMA \\
\hline BERTIOGA & Parque Estadual & $\begin{array}{l}\text { Parque Estadual da Serra } \\
\text { do Mar }\end{array}$ & $\begin{array}{l}\text { Decreto } 10.251 \text {, de 30/08/77 } 13.313 \\
06 / 03 / 79\end{array}$ & I. FLORESTAL \\
\hline BERTIOGA & Área Natural Tombada & $\begin{array}{l}\text { Serra do Mar e } \\
\text { Paranapiacaba }\end{array}$ & Resolução 40, de 06/06/85 & CONDEPHAAT \\
\hline BIRITIBA MIRIM & Área Natural Tombada & $\begin{array}{l}\text { Serra do Mar e } \\
\text { Paranapiacaba }\end{array}$ & Resolução 40, de 06/06/85 & CONDEPHAAT \\
\hline BIRITIBA MIRIM & Área de Proteção Ambiental & Varzea do Tiete & Lei 5.598 , de $06 / 02 / 87$ & SMA \\
\hline BIRITIBA MIRIM & Parque Estadual & $\begin{array}{l}\text { Parque Estadual da Serra } \\
\text { do Mar }\end{array}$ & $\begin{array}{l}\text { Decreto } 10.251 \text {, de 30/08/77, 13.313, } \\
06 / 03 / 79\end{array}$ & I. FLORESTAL \\
\hline $\begin{array}{l}\text { BRAGANCCA } \\
\text { PAULISTA }\end{array}$ & Área de Proteção Ambiental & $\begin{array}{l}\text { Piracicaba/Juqueri Mirim } \\
\text { ÁREA-II }\end{array}$ & Decreto 26.832 , de 11/03/87 & SMA \\
\hline CABREÚVA & Área de Proteção Ambiental & APA de Cabreuva & Lei 4.023 , de $22 / 05 / 84$ & SMA \\
\hline CABREÚVA & Área Natural Tombada & Serra do Japi & Resolução n. 11 de 08/03/83 & SMA \\
\hline CAIEIRAS & Parque Estadual & $\begin{array}{l}\text { Parque Estadual } \\
\text { Cantareira }\end{array}$ & Decreto 41.626 , de $30 / 01 / 83$ & I. FLORESTAL \\
\hline CAIEIRAS & Parque Estadual & Parque Estadual Juquery & Decreto 36.859 , de $05 / 06 / 93$ & I. FLORESTAL \\
\hline CAJAMAR & Área de Proteção Ambiental & APA de Cajamar & Lei 4.055 , de 22/05/84 & SMA \\
\hline CAJAMAR & Area Natural Tombada & Serra do Japi & Resolução n. 11 de 08/03/83 & CONDEPHAAT \\
\hline CARAPICUIBA & Área de Proteção Ambiental & Varzea do Tiete & Lei 5.598 , de $06 / 02 / 87$ & SMA \\
\hline COTIA & Reserva Estadual & R.E. Morro Grande & Lei 19.490 , de $04 / 04 / 70$ & SABESP \\
\hline CUBATÃO & Parque Estadual & $\begin{array}{l}\text { Parque Estadual da Serra } \\
\text { do Mar }\end{array}$ & $\begin{array}{l}\text { Decreto } 10.251 \text {, de 30/08/77, 13.313, } \\
06 / 03 / 79\end{array}$ & I. FLORESTAL \\
\hline $\begin{array}{l}\text { FRANCO DA } \\
\text { ROCHA }\end{array}$ & Parque Estadual & Parque Estadual Juquery & Decreto 36.859 , de 05/06/93 & I. FLORESTAL \\
\hline GUARUJÁ & Área Natural Tombada & Serra do Mar & Resolução 40, 06/06/85 & CONDEPHAAT \\
\hline GUARUJÁ & Área Natural Tombada & $\begin{array}{l}\text { M. Monduba, Pinho e } \\
\text { Icanhema }\end{array}$ & Resolução 66, de 10/12/85 & CONDEPHAAT \\
\hline GUARUJÁ & Área Natural Tombada & Serra do Guaraú & Resolução SC-048, de 18/12/92 & CONDEPHAAT \\
\hline GUARUJÁ & Área Natural Tombada & Morro do Botelho & Resolução 15, de 01/08/84 & CONDEPHAAT \\
\hline GUARULHOS & Parque Estadual & $\begin{array}{l}\text { Parque Estadual } \\
\text { Cantareira }\end{array}$ & Decreto 41.626 , de 30/01/83 & I. FLORESTAL \\
\hline GUARULHOS & Área de Proteção Ambiental & Varzea do Tiete & Lei 5.598 , de 06/02/87 & SMA \\
\hline IBIUNA & Parque Estadual & Parque Estadual Jurupara & Decreto 35.703/35.704, de 22/09/92 & I. FLORESTAL \\
\hline IBIUNA & Zona de Vida Silvestre & Serra do Mar & Decreto 22.717 , de 21/09/84 & SMA \\
\hline IBIUNA & Ärea de Proteção Ambiental & Serra do Mar & Decreto 22.717 , de 21/09/84 & SMA \\
\hline ITANHAÉM & Parque Estadual & $\begin{array}{l}\text { Parque Estadual da Serra } \\
\text { do Mar }\end{array}$ & $\begin{array}{l}\text { Decreto } 10.251 \text {, de 30/08/77, 13.313, } \\
06 / 03 / 79\end{array}$ & I. FLORESTAL \\
\hline ITANHAÉM & Área Natural Tombada & $\begin{array}{l}\text { Serra do Mar e } \\
\text { Paranapiacaba }\end{array}$ & Resolução 40, de 06/06/85 & CONDEPHAAT \\
\hline $\begin{array}{l}\text { ITAQUAQUECETU } \\
\text { BA }\end{array}$ & Área de Proteção Ambiental & Varzea do Tiete & Lei 5.598 , de $06 / 02 / 87$ & SMA \\
\hline ITARIRI & Parque Estadual & $\begin{array}{l}\text { Parque Estadual da Serra } \\
\text { do Mar }\end{array}$ & $\begin{array}{l}\text { Decreto } 10.251 \text {, de 30/08/77, 13.313, } \\
06 / 03 / 79\end{array}$ & I. FLORESTAL \\
\hline ITARIRI & Área Natural Tombada & $\begin{array}{l}\text { Serra do Mar e } \\
\text { Paranapiacaba }\end{array}$ & Resolução 40, de 06/06/85 & CONDEPHAAT \\
\hline ITARIRI & Estação Ecológica Estadual & $\begin{array}{l}\text { Estação Ecológica Juréia- } \\
\text { Itatins }\end{array}$ & Lei 5.649 , de 28/04/87 & I. FLORESTAL \\
\hline JOANÓPOLIS & Área de Proteção Ambiental & $\begin{array}{l}\text { Piracicaba/Juqueri Mirim } \\
\text { ÁREA-II }\end{array}$ & Decreto 26.832 , de 11/03/87 & SMA \\
\hline JUNDIAÍ & Área de Proteção Ambiental & APA de Jundiai & Lei 4.905 , de $12 / 06 / 84$ & SMA \\
\hline JUNDIAÍ & Area Natural Tombada & Serra do Japi & Resolução 11, de 08/03/83 & CONDEPHAAT \\
\hline JUQUITIBA & Parque Estadual & $\begin{array}{l}\text { Parque Estadual da Serra } \\
\text { do Mar }\end{array}$ & $\begin{array}{l}\text { Decreto } 10.251 \text {, de } 30 / 08 / 77,13.313 \text {, } \\
06 / 03 / 79\end{array}$ & I. FLORESTAL \\
\hline JUQUITIBA & Arrea de Proteção Ambiental & Serra do Mar & Decreto 22.717 , de 21/09/84 & SMA \\
\hline JUQUITIBA & Zona de Vida Silvestre & Serra do Mar & Decreto 22.717 , de 21/09/84 & SMA \\
\hline MAIRIPORÃ & Parque Estadual & Parque Estadual & Decreto 41.626 , de $30 / 01 / 83$ & \\
\hline
\end{tabular}


Tabela 1: Áreas protegidas e unidades de conservação da reserva da biosfera do cinturão verde de São Paulo (continuação)

\begin{tabular}{|c|c|c|c|c|}
\hline MUNICIPIO & TIPO DE UNIDADE & NOME & LEGISLAÇĀO & RESPONSAVEL \\
\hline $\begin{array}{l}\text { MOGI DAS } \\
\text { CRUZES }\end{array}$ & Área de Proteção Ambiental & Varzea do Tiete & Lei 5.598 , de 06/02/87 & SMA \\
\hline $\begin{array}{l}\text { MOGI DAS } \\
\text { CRUZES }\end{array}$ & Estação Ecológ ic a Estadual & Estação Ecológica Itapeti & Decreto 26.890 , de $12 / 03 / 87$ & I. FLORESTAL \\
\hline $\begin{array}{l}\text { MOGI DAS } \\
\text { CRUZES }\end{array}$ & Parque Es tadual & $\begin{array}{l}\text { Parque Estadual da Serra } \\
\text { do Mar }\end{array}$ & $\begin{array}{l}\text { Decreto } 10.251 \text {, de } 30 / 08 / 77,13.313 \text {, } \\
06 / 03 / 79\end{array}$ & I. FLORESTAL \\
\hline $\begin{array}{l}\text { MOGI DAS } \\
\text { CRUZES }\end{array}$ & Área Natural Tombada & $\begin{array}{l}\text { Serra do Mar e } \\
\text { Paranapiacaba }\end{array}$ & Resolução 40, de 06/06/85 & CONDEPHAAT \\
\hline MOGI GUAÇU & Estação Ecológic a Estadual & $\begin{array}{l}\text { Estação Ecológica Mogi } \\
\text { Guaçu }\end{array}$ & Decreto 22.336 , de 07/06/84 & I. FLORESTAL \\
\hline MONGAGUÁ & Parque Es tadual & $\begin{array}{l}\text { Parque Estadual da Serra } \\
\text { do Mar }\end{array}$ & $\begin{array}{l}\text { Decreto } 10.251 \text {, de } 30 / 08 / 77,13.313 \text {, } \\
06 / 03 / 79\end{array}$ & I. FLORESTAL \\
\hline $\begin{array}{l}\text { NAZARÉ } \\
\text { PAULISTA }\end{array}$ & Área de Proteção Ambiental & $\begin{array}{l}\text { Piracicaba/Juqueri Mirim } \\
\text { ÁREA-II }\end{array}$ & Decreto 26.832 , de $11 / 03 / 87$ & SMA \\
\hline OSASCO & Área de Proteção Ambiental & Varzea do Tiete & Lei 5.598 , de 06/02/87 & SMA \\
\hline PARAIBUNA & Parque Estadual & $\begin{array}{l}\text { Parque Estadual da Serra } \\
\text { do Mar }\end{array}$ & $\begin{array}{l}\text { Decreto } 10.251 \text {, de } 30 / 08 / 77,13.313 \text {, } \\
06 / 03 / 79\end{array}$ & I. FLORESTAL \\
\hline $\begin{array}{l}\text { PEDRO DE } \\
\text { TOLEDO }\end{array}$ & Parque Es tadual & $\begin{array}{l}\text { Parque Estadual da Serra } \\
\text { do Mar }\end{array}$ & $\begin{array}{l}\text { Decreto } 10.251 \text {, de 30/08/77, 13.313, } \\
\text { 06/03/79 }\end{array}$ & I. FLORESTAL \\
\hline $\begin{array}{l}\text { PEDRO DE } \\
\text { TOLEDO }\end{array}$ & Área de Proteção Ambiental & Serra do Mar & Decreto 22.717 , de $21 / 09 / 84$ & SMA \\
\hline PERUÍBE & Parque Es tadual & $\begin{array}{l}\text { Parque Estadual da Serra } \\
\text { do Mar }\end{array}$ & $\begin{array}{l}\text { Decreto } 10.251 \text {, de } 30 / 08 / 77,13.313 \text {, } \\
06 / 03 / 79\end{array}$ & I. FLORESTAL \\
\hline PERUÍBE & Estação Ecológ ic a Estadual & $\begin{array}{l}\text { Estação Ecológica Juréia- } \\
\text { Itatins }\end{array}$ & Lei 5.649 , de $28 / 04 / 87$ & I. FLORESTAL \\
\hline PERUÍBE & Área Natural Tombada & $\begin{array}{l}\text { Serra do Mar e } \\
\text { Paranapiacaba }\end{array}$ & Resolução 40, de 06/06/85 & CONDEPHAAT \\
\hline PIRACAIA & Área de Proteção Ambiental & $\begin{array}{l}\text { Piracicaba/Juqueri Mirim } \\
\text { ÁREA-II }\end{array}$ & Decreto 26.832 , de $11 / 03 / 87$ & SMA \\
\hline $\begin{array}{l}\text { PIRAPORA DO } \\
\text { BOM JESUS }\end{array}$ & Area Natural Tombada & Serra do Japi & Resolução n. 11, de 08/03/83 & CONDEPHAAT \\
\hline $\begin{array}{l}\text { PIRAPORA DO } \\
\text { BOM JESUS }\end{array}$ & Area Natural Tombada & Serra do Boturuna & Resolução 17 ,de 04/08/83 & CONDEPHAAT \\
\hline POÁ & Área de Proteção Ambiental & Varzea do Tiete & Lei 5.598 , de 06/02/87 & SMA \\
\hline PORTO FERREIRA & Parque Es tadual & $\begin{array}{l}\text { Parque Estadual Porto } \\
\text { Ferreira }\end{array}$ & Decreto 26.891 , de 12/03/87 & I. FLORESTAL \\
\hline PRAIA GRANDE & Parque Estadual & $\begin{array}{l}\text { Parque Estadual da Serra } \\
\text { do Mar }\end{array}$ & $\begin{array}{l}\text { Decreto } 10.251 \text {, de } 30 / 08 / 77,13.313 \text {, } \\
06 / 03 / 79\end{array}$ & I. FLORESTAL \\
\hline PRAIA GRANDE & Parque Es tadual & $\begin{array}{l}\text { Parque Estadual Xixová- } \\
\text { Japuí }\end{array}$ & Decreto 37.536 , de $27 / 09 / 93$ & I. FLORESTAL \\
\hline SALESÓPOLIS & Área de Proteção Ambiental & Varzea do Tiete & Lei 5.598, de 06/02/87 & SMA \\
\hline SALESÓPOLIS & Parque Estadual & Nascentes do Rio Tiete & Decreto 29.181 , de 11/11/88 & SMA \\
\hline SALESÓPOLIS & Parque Estadual & $\begin{array}{l}\text { Parque Estadual da Serra } \\
\text { do Mar }\end{array}$ & $\begin{array}{l}\text { Decreto 10.251, de 30/08/77, 13.313, } \\
\text { 06/03/79 }\end{array}$ & I. FLORESTAL \\
\hline SALESÓPOLIS & Área Natural Tombada & $\begin{array}{l}\text { Serra do Mar e } \\
\text { Paranapiacaba }\end{array}$ & Resolução 40, de 06/06/85 & CONDEPHAAT \\
\hline SALESÓPOLIS & Area Natural Tombada & Nascentes do Rio Tiete & Resolução 06 de 21/02/90 & SMA \\
\hline SANTO ANDRÉ & Área de Proteção Ambiental & $\begin{array}{l}\text { APA Haras de SÃO } \\
\text { Bemardo }\end{array}$ & Lei 5.745 de $10 / 07 / 87$ & SMA \\
\hline SANTO ANDRÉ & Area Natural Tombada & $\begin{array}{l}\text { Nucleo Urb. de } \\
\text { Paranapiacaba }\end{array}$ & Resolução s/n de 30/09/87 & SMA \\
\hline SANTO ANDRÉ & Parque Estadual & $\begin{array}{l}\text { Parque Estadual da Serra } \\
\text { do Mar }\end{array}$ & $\begin{array}{l}\text { Decreto } 10.251 \text {, de } 30 / 08 / 77,13.313 \text {, } \\
06 / 03 / 79\end{array}$ & I. FLORESTAL \\
\hline SANTO ANDRÉ & Reserva Biológica & $\begin{array}{l}\text { Reserva Bioçógica } \\
\text { Paranapiacaba }\end{array}$ & Decreto 12.753 , de $12 / 06 / 42$ & I. Botânica \\
\hline SANTOS & Parque Estadual & $\begin{array}{l}\text { Parque Estadual da Serra } \\
\text { do Mar }\end{array}$ & $\begin{array}{l}\text { Decreto } 10.251 \text {, de } 30 / 08 / 77,13.313 \text {, } \\
06 / 03 / 79\end{array}$ & I. FLORESTAL \\
\hline SANTOS & Parque Estadual & $\begin{array}{l}\text { Pq. Est.Marinho da Laje } \\
\text { de Santos }\end{array}$ & Decreto 37.537 , de $27 / 09 / 93$ & I. FLORESTAL \\
\hline SANTOS & Área Natural Tombada & $\begin{array}{l}\text { Serra do Mar e } \\
\text { Paranapiacaba }\end{array}$ & Resolução 40, de 06/06/85 & CONDEPHAAT \\
\hline SANTOS & Área Natural Tombada & Vale do Quilombo & Resolução 60, de 22/10/88 & CONDEPHAAT \\
\hline $\begin{array}{l}\text { SÃO BERNARDO } \\
\text { DO CAMPO }\end{array}$ & Parque Estadual & $\begin{array}{l}\text { Parque Estadual da Serra } \\
\text { do Mar }\end{array}$ & $\begin{array}{l}\text { Decreto } 10.251 \text {, de } 30 / 08 / 77,13.313 \text {, } \\
06 / 03 / 79\end{array}$ & I. FLORESTAL \\
\hline
\end{tabular}


Tabela 1: Áreas protegidas e unidades de conservação da reserva da biosfera do cinturão verde de São Paulo (continuação)

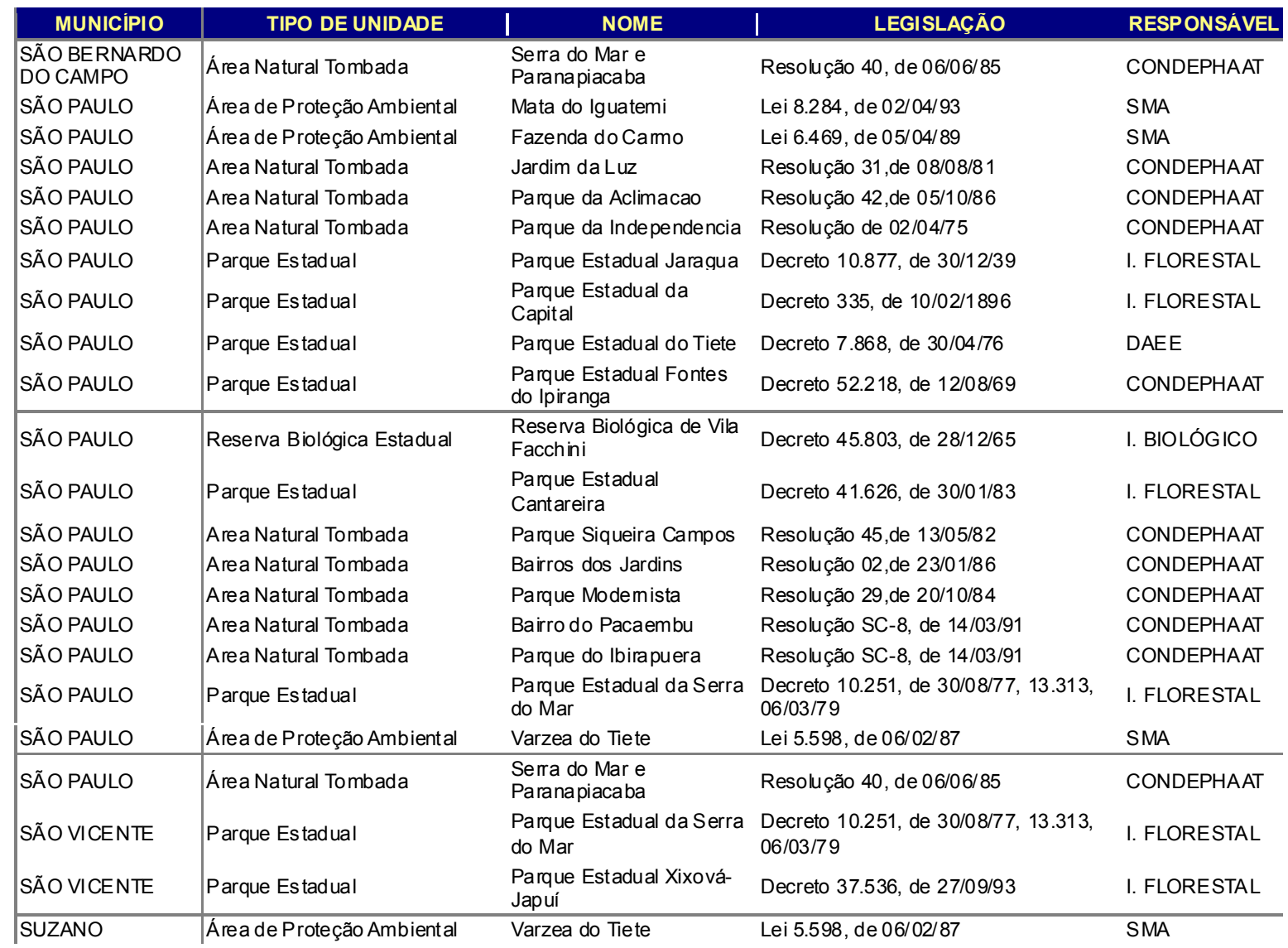

A ordem ambiental internacional (Ribeiro, 2001) é uma resposta a esse desequilíbrio de forças entre países. Com todas as falhas e imperfeições que se possam apontar, ela busca estabelecer um caminho de diálogo multilateral ao possibilitar a interação entre partes muito desiguais. É evidente que alguns setores sociais são prejudicados e outros atendidos, prevalecendo um realismo político sem armas, no qual as partes buscam salvaguardar o interesse nacional (Ribeiro, 2001). Também é evidente que novas oportunidades surgem na escala internacional, o que pode alterar a posição de um país no cenário internacional. Como ocorre nas escalas nacionais e regionais, é preciso identificar quem ganha e quem perde a cada rodada da ordem ambiental internacional.

A governança pode ser definida como um sistema de gestão que combina diversos atores sociais, sejam eles estatais, representantes da sociedade civil ou empresários. A intenção é reunir os principais interlocutores para ajustar interesses e evitar conflitos ou até mesmo a confrontação. Como fazer isso na escala internacional?

As convenções internacionais sobre ambiente têm possibilitado reunir diversos atores. Entretanto, pode-se criticá-las por deixarem as decisões apenas entre os países membros. Nesse caso caberia lembrar as críticas de ausência de democracia, como bem apontou Altvater (1999). Mesmo com todas essas dificuldades, é inegável que a série de convenções que buscam regular a ação humana em escala internacional, mesmo que a decisão fique a cargo dos países, é uma alternativa real para evitar confrontação.

É preciso lembrar ainda que em muitas situações as organizações não governamentais (ONGs) e os movimentos sociais acabaram influenciando a pauta das convenções internacionais sobre meio ambiente, o que não é pouco expressivo. Além disso, a realização de reuniões paralelas às organizadas pelo Programa 
das Nações Unidas para o Meio Ambiente - PNUMA, também oferece a possibilidade de encontros de representantes de diversos países por meio da sociedade civil organizada e até mesmo pelos estados, em geral convidados e expor seus pontos de vista sobre os problemas ambientais. É evidente que tais reuniões não têm caráter decisório, mas negar sua capacidade de mobilização e de influenciar a opinião pública seria um erro.

As principais ONGs que atuam na escala mundial estão organizadas para influenciar decisões de países. Elas geram produtos e análises realizadas por especialistas que se contrapõem às posições oficiais. É freqüente promoverem ações espetaculares para chamar atenção da grande imprensa e, desse modo, veicularem suas visões para a opinião pública. Além disso, acabam tornando-se parceiras de governos, de comunidades tradicionais e de movimentos sociais ao financiarem projetos, cujas finalidades e objetivos nem sempre são explícitos.

A ordem ambiental internacional também pode ser compreendida na perspectiva da governança ambiental ao estimular o surgimento de redes sociais que discutem temas como proteção da diversidade biológica e do conhecimento de populações tradicionais, formas de atenuar o aquecimento global e de diminuir o buraco da camada de ozônio. Muitas dessas redes internacionais são criadas para pressionar decisões de governos e de organismos multilaterais.

Mais uma possibilidade de definir governança foi difundida pela Comissão sobre Governança Global que, em documento de 1995, apontou que ela deve ser estabelecida sobre a gestão de bens comuns (Commission on Global Governance, 1995). Essa definição remete à discussão do que é bem comum.

Os recursos naturais não são entendidos como comuns. Nem poderiam, dado o sistema hegemônico, o capitalista, que busca ganhos em qualquer frente e os trata como fonte de acumulação de capital. Por isso eles são entendidos como uma mercadoria, muitas vezes, rara, e despertam disputas políticas, que levam, muitas vezes, a conflitos.

Outra escala de análise centra os estudos na abertura da gestão pública à participação da sociedade civil para elaborar políticas públicas. Nesse caso é preciso considerar como a institucionalização da participação social permite rupturas na dinâmica da gestão dos recursos naturais. Este processo de envolvimento social pode ser verificado no Brasil nos Comitês de Bacia Hidrográfica ou os diversos Conselhos de Meio Ambiente, como o Conselho Nacional de Meio Ambiente ou no Conselho Estadual de Meio Ambiente de São Paulo. Esta escala também pode ser empregada para a análise, por exemplo, de Conselhos Gestores de Unidades de Conservação e para os Conselhos Municipais de Meio Ambiente, tal qual ocorre, por exemplo, na Reserva da Biosfera do Cinturão Verde da Cidade de São Paulo.

Adentrando mais no caso brasileiro, verifica-se que a participação está focada em novos foros que passaram a estabelecer a presença da sociedade civil. Da luta pela democracia, como ocorreu até meados da década de 1980, a população brasileira vê-se diante de um universo de conselhos e comitês que exigem qualificação nas intervenções.

O chamado "empoderamento" é uma das conseqüências dessa forma de participação social. Para tal é necessário estabelecer um aprimoramento constante da formação de lideranças. Nota-se que isso ocorre com mais facilidade para a formação política que para a capacitação técnica. É preciso qualificar também tecnicamente os que participam de conselhos gestores ambientais nas diversas escalas. Basta assistir a uma reunião para observar que muitas vezes as propostas mais inviáveis e sem possibilidade de implementação técnica surgem da sociedade civil. Por outro lado, é preciso que os técnicos sejam mais sensíveis às demandas sociais. É preciso ter coragem para buscar alternativas quando o social se impõe sobre o técnico. Logo, muitos técnicos também necessitam de mais capacitação para apreenderem demandas sociais legítimas oriundas de grupos de pressão populares e aceitarem alternativas mais políticas que técnicas.

O sociólogo Jacobi (2003), destaca que a governança envolve a noção de poder social que media as relações entre Estado e sociedade civil. Ela permitiria a formação de alianças e a cooperação, sem deixar de expor também conflitos que decorrem do impacto das assimetrias sociais e de seus impactos no meio ambiente e das formas de resistência, organização e participação dos diversos atores envolvidos. 
Esta noção se insere no plano das relações de poder e do fortalecimento de práticas de controle social e constituição de públicos participativos. Já para o economista Cavalcanti (2004), o maior problema é a aplicação das normas existentes no país. Apesar da existência de diversos conselhos, muitos deles funcionam de modo instável com uma frágil inserção popular.

A governança na escala nacional, regional e local deve estar articulada à esfera internacional, quando se trata de tema que esta vinculado a um tratado multilateral. A internalização de um tema externo não pode ser realizada sem ponderar demandas regionais e locais.

O caso da Reserva da Biosfera do Cinturão Verde de São Paulo é interessante pois engloba diversas escalas de governança. Inicialmente, na escala internacional temos a UNESCO. Depois, ele permite analisar a escala estadual por ser responsabilidade da Secretaria de Estado de Meio Ambiente do Estado de São Paulo.

Para que a governança possa ser identificada é necessário existirem alguns requisitos, que depois serão comparados com a situação da Reserva da Biosfera do Cinturão Verde.

Antes de mais nada, é fundamental reunir pessoas para discutir um tema complexo. Uma unidade de conservação envolve diversos agentes sociais. Eles podem ser habitantes do lugar a ser protegido e podem ainda viver no entorno, mas desenvolver atividades na área protegida. As restrições de uso da área protegida vai afetar o estilo de vida dessas populações, o que pode desencadear resistência à proteção ambiental.

Por isso é preciso identificar os agentes e verificar a legitimidade que conquistaram para tratar dos temas em discussão. Depois, é preciso estabelecer um fórum para que os debates ocorram. E, fundamentalmente, deve haver mobilização social para os assuntos em discussão.

A presença de redes de ação social é outro fator relevante. Eles facilitam a expressão popular e permitem contato também com membros das comunidades epistêmicas, membros de associações científicas que se dedicam ao tema, tanto na condição de investigadores, quanto na condição de atores envolvidos com as questões em discussão.

Por fim, é fundamental que o estado assimile as decisões, que nesse caso são externas a ele. Para tal, é vital existirem instrumentos jurídicos que incorporem a participação social para aplicação das decisões.

\section{A ação da UNESCO. Ação?}

Segundo entrevista com gestores da Reserva da Biosfera do Cinturão Verde da Cidade de São Paulo, realizada pelo autor em maio de 2008, a UNESCO pouco colaborou com a institucionalização da área protegida. Nas palavras de um deles, "trata-se de um selo que agrega valor para que se consigam financiamentos internos e externos". Ainda assim, ele reconheceu que "no início, a UNESCO colaborou bastante ao capacitar técnicos para a gestão da reserva, mas depois, praticamente deixou ao cargo desses a gestão". O que não seria de todo ruim, já que os povos devem gerir suas reservas naturais. Mas a dificuldade surgiu da falta de financiamento, já que "a UNESCO deixou de enviar recursos e depois a Secretaria teve que assumir a manutenção da reserva, com todas as limitações que possui, além de ter de cuidar de muitas outras no estado de São Paulo".

O depoimento do técnico é elucidador. Dele se depreendem alguns aspectos relevantes: a intenção da UNESCO em proteger uma área sensível e de elevada biodiversidade, a preocupação com a formação inicial dos técnicos responsáveis pela gestão da área protegida, e, depois, a ausência de recursos para a manutenção da reserva.

Não resta dúvida que a UNESCO, fundada em 1946 e sediada em Paris, França, foi, até a década de 1970, o principal órgão da ONU para tratar da questão ambiental. Mesmo voltada à promoção do intercâmbio científico e tecnológico entre os países-membros da ONU e a implementar programas de educação, ela encontrou nos temas ambientais uma função relevante. Isso perdurou até a criação do Programa das Nações Unidas para o Meio Ambiente - PNUMA, criado por decisão da Conferência de Estocolmo, de 1972, mas que só ganhou sede em Nairobi em 1986. 
A educação ambiental foi o grande alvo das ações da UNESCO. Porém, já em 1970 foi criado o Programa O Homem e a Biosfera, resultado da Conferência Intergovernamental de Especialistas sobre as Bases Científicas para Uso e Conservação Racionais dos Recursos da Biosfera, ou simplesmente Conferência da Biosfera, reunião que ela promoveu em 1968 em Paris. O Programa definiu que cada país deveria criar comitês nacionais para promover pesquisas que permitissem uma comparação das condições de manutenção da biodiversidade no mundo, bem como identificar pressões sobre sua conservação.

As Reservas da Biosfera, áreas naturais protegidas com elevado interesse ecológico, também deveriam ser usadas para a promoção de práticas educacionais que estimulassem a conservação dos recursos naturais. Elas estavam baseadas em uma visão que separa a natureza da sociedade, de tal modo que foram criticadas por movimentos sociais que viam nelas uma forma de exclusão de grupos humanos que viviam nas áreas. Isso foi alterado aos poucos, de modo que atualmente se encontram Reservas da Biosfera com presença de população local, que vive de modo a não alterar significativamente as condições naturais e a reprodução do ciclo da vida.

Outro aspecto a destacar ainda em relação à manutenção da diversidade biológica é a intenção de realizar inventários com o acervo de informação genética disponível nas áreas protegidas. Um dos objetivos do Programa O Homem a a Biosfera era justamente disseminar técnicas comuns de catalogação de espécies de modo a facilitar sua identificação, antecipando a introdução de procedimentos científicos hoje difundidos entre vários países.

A formação dos primeiros técnicos dedicados à reserva no estado de São Paulo era vital às intenções da UNESCO. Sem isso, como garantir que a conservação da Reserva da Biosfera do Cinturão Verde da Cidade de São Paulo fosse enquadrada nas normas e procedimentos difundidos mundialmente?

Segundo informou um dos técnicos ao autor, na mesma entrevista de maio de 2008, os cursos de capacitação eram oferecidos no Brasil e voltados à realidade local, mas abrindo oportunidades para a criação de ações locais consideradas adequadas à conservação da biodiversidade. Nas palavras dele "os cursos tratavam de experiências de gestão de áreas protegidas mas havia tempo para discutir como proceder no caso da Reserva da Biosfera do Cinturão Verde da Cidade de São Paulo". Para ele, isso "estimulou os técnicos, que não eram submetidos a um modelo externo, mas sim a diretrizes técnicas de como proceder". Talvez por isso esse técnico, que estava entre os primeiros a serem capacitados, mantenhase até hoje vinculado à Reserva da Biosfera do Cinturão Verde da Cidade de São Paulo.

Capacitação técnica não é apenas dizer o que fazer em determinadas situações problema. Trata-se de influenciar na forma de resolver as questões, de modo a permitir uma assimilação temática e de procedimentos que resulte em um determinado padrão de comportamento que permita estabelecer resultados e comparações. Era justamente esse o objetivo da UNESCO.

Segundo informou outro técnico, entrevistado na mesma ocasião que o anterior, o Programa Jovens da Biosfera, por exemplo, resultou de uma iniciativa da UNESCO mas que foi aprimorada pela equipe local de modo a torná-lo referência na escala latino-americana. Ou seja, autonomia, desde que cumpra os requisitos mínimos, resulta em inovação e aprimoramento das técnicas e objetivos da conservação ambiental.

Com o argumento de que os programas devem criar alternativas à sua manutenção, o aparente abandono financeiro se justifica. Ou seja, dota-se uma quantia inicial para estabelecer uma maneira de operar e, depois, deixam-se os técnicos e governos à sua capacidade de levantar recursos.

Esse procedimento é louvável do ponto de vista da autonomia da gestão dos recursos naturais, mas ao mesmo tempo deixa em uma posição confortável a organização internacional, que não é obrigada a financiar ações nem a repassar fundos à conservação ambiental. A agregação de um valor por se tratar de uma Reserva da Biosfera é importante, mas insuficiente, já que muitas vezes as dificuldades surgem exatamente na manutenção das áreas protegidas. Ou seja, é muito mais fácil criar uma unidade de conservação que mantê-la, além do que possui muito mais apelo à opinião pública que enviar dinheiro para uma situação consolidada.

A UNESCO acerta quando destina um aporte inicial de recursos, mas deveria ao menos criar algumas linhas de financiamento para as reservas da biosfera de modo a estimular e mobilizar o corpo técnico a 
obter recursos no interior desse órgão da $\mathrm{ONU}$ e não deixá-los à mercê dos financiamentos de fundações privadas ou de ONGs internacionais, que muitas vezes estimulam ações que podem levar a conflitos com os objetivos das reservas.

\section{A ação da Secretaria Estadual do Meio Ambiente do Estado de São Paulo}

Curiosamente coube ao estado de São Paulo a gestão de uma área protegida que resultou de uma mobilização social contra uma grande obra viária que ele desejava realizar. Ou seja, a intenção de construir uma via que circunscrevesse a Região Metropolitana de São Paulo gerou uma nova obrigação ao estado de São Paulo, além de adiar a obra.

De acordo com regulamentação Federal, por meio do Sistema Nacional de Unidades de Conservação - SNUC, resultado de mais de 10 anos de discussão no Congresso Nacional e criado por meio da Lei Federal 9985, de 18 de julho de 2000, regulamentada pelo Decreto Federal 4340, de 22 de agosto de 2002, cada unidade de conservação deve ter um Conselho Gestor. Não foi por outra razão que a Secretaria de Estado do Meio Ambiente de São Paulo, por meio do Decreto 47.094, de 18 de setembro de 2002, menos de um mês após a regulamentação do SNUC, instituiu o Comitê Estadual da Reserva da Biosfera da Mata Atlântica no Estado de São Paulo, porém, incluiu no mesmo instrumento jurídico o Conselho de Gestão da Reserva da Biosfera do Cinturão Verde da Cidade de São Paulo.

Uma análise dos termos desse Decreto é importante para verificar a abrangência e restrições de tal ato. Inicialmente se destaca o parágrafo único, que dispõe:

Parágrafo único - As recomendações provenientes do Comitê Estadual da Reserva da Biosfera da Mata Atlântica no Estado de São Paulo serão indicativas para os setores público e privado (grifo do autor).

Ou seja, as decisões do Comitê são apenas indicativas e não possuem caráter deliberativo. Trata-se, antes de mais nada, de um conselho consultivo, que menos que ditar os rumos das negociações que envolvem a conservação da área deve indicar possibilidades que serão avaliadas pelo órgão executivo. No $\S 3^{\circ}$ do artigo $6^{\circ}$ do Decreto 47.094, $\S 3^{\circ}$, define-se o órgão:

$\S 3^{\circ}$ - Os procedimentos para reestruturação e implementação do Conselho de Gestão da Reserva da Biosfera do Cinturão Verde da Cidade de São Paulo serão encaminhados pelo Instituto Florestal, da Secretaria do Meio Ambiente, órgão que exercerá a coordenação executiva desta Reserva (grifos do autor).

Cabe ao Instituto Florestal ${ }^{3}$ a coordenação executiva, isto é, operar a gestão da Reserva da Biosfera da Mata Atlântica no Estado de São Paulo. A mobilização social para a criação da Reserva da Biosfera conseguiu, ao final, estabelecer uma área a ser conservada, mas não a gestão direta sobre ela.

Não faltam argumentos para justificar esse tipo de solução. Um deles é a falta de preparo técnico da sociedade civil. De certo modo, em algumas situações surgem realmente propostas que não podem ser operacionalizadas, seja por impedimentos técnicos, seja por restrições jurídicas. Entretanto, isso não quer dizer que a sociedade civil não deva ser ouvida, principalmente em suas demandas socioambientais.

Dar voz à sociedade civil é, fundamentalmente, permitir a expressão de valores culturais, de costumes e de demandas materiais concretas, que não colocam em risco a reprodução dos processos naturais e que permitem a manutenção das condições do sítio natural. Por isso a reivindicação de uma área para proteção é mais importante quando vem acompanhada pela mobilização social. De nada vale criar uma área natural protegida sem manter a população que nela vive e que, apesar de nela viver, não impediu a reprodução de processos naturais de modo a prejudicar suas manifestações.

Por isso os técnicos devem ser capacitados para saberem identificar demandas sociais que garantam a reprodução do estilo de vida da população e não expulsá-la da área, tornando-a um vazio humano em prol de um uso futuro dos recursos naturais que ela possui. 
Outro argumento usado para deixar a gestão com o estado é o caráter público das áreas protegidas. Realmente esse aspecto é fundamental. Cabe ao estado manter o interesse público. Mas ele seria neutro em suas decisões? Essa é a grande dificuldade.

Imaginar que o caráter público é comum a todos interesses da sociedade é uma ilusão. Não resta dúvida que muitas vezes interesses privados são difundidos como públicos e expressam ideologias alheias à maioria da população. O caso da Reserva da Biosfera do Cinturão Verde da Cidade de São Paulo é emblemático. A mobilização inicial que a criou não se repetiu por ocasião do novo projeto de construção do RodoAnel Metropolitano, o que resulta em uma verdadeira ameaça à manutenção da área protegida criada no passado. É de se perguntar porque tal mobilização não se repetiu? Teriam mudados os objetivos da obra? Teriam sido alteradas as características ambientais da área protegida de modo a não ser mais necessário a restrição ao seu uso? Nenhuma das situações foram alteradas.

O que mudou foi o bloco no poder no governo estadual. Em 1994, ano de criação da Reserva da Biosfera do Cinturão Verde da Cidade de São Paulo, o governador era Luis Antonio Fleury, do Partido do Movimento Democrático do Brasil, que se notabilizou por promover uma ação policial que resultou em mais de 100 mortes em um presídio da capital paulista e que teve nessa ação uma oportunidade de tentar mudar sua imagem. Além disso, vivia-se o espírito da Conferência do Rio, de 1992, momento em que ações de conservação ambiental tinha apelo popular. Já em 2002 o governador era Geraldo Alckmin, substituído depois por José Serra, em 2006, ambos do Partido da Social Democracia do Brasil.

A alternância no poder é resultado da democracia, e deve ser praticada. Mas basta um intervalo de menos de 10 anos para se perceber que o caráter público muda aos sabores dos partidos políticos.

\section{O Conselho Gestor da Reserva da Biosfera do Cinturão Verde da Cidade de São Paulo}

De acordo com o já citado SNUC, cabe criar um conselho gestor para a Reserva da Biosfera do Cinturão Verde da Cidade de São Paulo. A Secretaria Estadual de Meio Ambiente do Estado de São Paulo aproveitou o mesmo Decreto 47.094 para estabelecê-lo, ao definir no artigo $6^{\circ}$ que:

"O Comitê Estadual poderá criar Sub-Comitês Estaduais da Reserva da Biosfera da Mata Atlântica com a finalidade de apoiar a implantação da reserva nas diferentes regiões do Estado, ficando desde já definida a criação de 3 Sub-Comitês:

II - Sub-Comitê Estadual da Reserva da Biosfera do Cinturão Verde da Cidade de São Paulo, parte integrante da Reserva da Biosfera da Mata Atlântica (incluindo a Baixada Santista);

$\S 1^{\circ}$ - A composição dos Sub-Comitês será aprovada pelo Comitê Estadual e deverá considerar a representatividade e a paridade de entidades governamentais e da sociedade civil atuante na região de abrangência de cada Sub-Comitê.

$\S 2^{\circ}$ - O Sub-Comitê da Reserva da Biosfera do Cinturão Verde da Cidade de São Paulo corresponde ao Conselho de Gestão da aludida Reserva."

Ou seja, o mesmo decreto criou a Reserva e seus meios de gestão, inclusive o Conselho Gestor, cuja composição deveria ser paritária entre órgãos governamentais e representantes da sociedade civil. Ele também dispôs sobre a composição do Conselho, nos seguintes termos:

O Comitê será composto de 14 (catorze) membros e respectivos suplentes, representando, paritariamente, o Poder Público e a Sociedade Civil, na forma seguinte:

I - Do Poder Público:

a) 2 (dois) representantes da Secretaria do Meio Ambiente, sendo um deles do Instituto Florestal e outro da Coordenadoria de Planejamento Ambiental - CPLA;

b) 1 (um) representante da Fundação Florestal do Estado de São Paulo; 
c) 1 (um) representante do CONDEPHAAT, da Secretaria da Cultura;

d) 1 (um) representante da Secretaria de Economia e Planejamento;

e) 1 (um) representante dos Municípios incluídos na Reserva da Biosfera da Mata Atlântica, localizados no Estado de São Paulo;

f) 1 (um) representante do IBAMA - Instituto Brasileiro do Meio Ambiente e dos Recursos Naturais Renováveis, do Ministério do Meio Ambiente, mediante convite;

II - Da sociedade civil:

a) 2 (dois) representantes de ONG's - Organizações Não Governamentais, ambientalistas, devidamente registradas nos termos da legislação em vigor;

b) 2 (dois) representantes de comunidades locais de moradores;

c) 2 (dois) representantes da comunidade científica;

d) 1 (um) representante do setor empresarial.

Observa-se entre os representantes de órgãos estatais cinco vinculados à gestão do ambiental, quais sejam, o Instituto Florestal, órgão executivo da Reserva da Biosfera do Cinturão Verde da Cidade de São Paulo, a Coordenadoria de Planejamento Ambiental e a Fundação Florestal, todos vinculados à Secretaria Estadual de Meio Ambiente do Estado de São Paulo, o Instituto Brasileiro do Meio Ambiente e dos Recursos Naturais Renováveis, órgão Federal que tem que estar presente por ser o vínculo formal com a UNESCO e o Conselho de Defesa do Patrimônio Histórico, Arqueológico, Artístico e Turístico do estado de São Paulo, responsável pelo tombamento da Serra do Mar.

Uma análise do ponto de vista das escalas de poder do estatal indica que o governo do estado de São Paulo possui cinco entre sete votos, enquanto que os 73 municípios em cujos territórios se distribui a Reserva da Biosfera do Cinturão Verde da Cidade de São Paulo elegem apenas um representante, que tem o mesmo peso que o indicado pelo poder Federal. Ou seja, entre os membros do estado, o governo estadual detém ampla maioria, que é exercida por órgãos vinculados à gestão ambiental.

Em relação à sociedade civil, existe um certo equilíbrio. Os moradores têm dois assentos, mesma quantidade que as ONGs ambientalistas e que a comunidade acadêmica. Nota-se ainda a presença do setor empresarial e pergunta-se porque o setor sindical não foi lembrado.

A pergunta que se pode fazer é se existe convergência de demandas entre os moradores e as ONGs e mesmo entre as universidades, que podem ser públicas e, a depender da ingerência política que admitem ou não, podem acabar por ser mais um porta-voz do governo estadual. Ou nos termos indicados pelo economista espanhol Martinez-Alier (2007), se não existe um conflito distributivo ecológico que se expressa por uma linguagem distinta entre os sujeitos sociais.

Também não fica claro que tipo de associação ambientalista pode ocupar as cadeiras, já que elas devem ser eleitas entre as que estão cadastradas na Secretaria Estadual de Meio Ambiente de São Paulo. Em geral, verifica-se grande articulação e disputa política para ser indicado a compor conselhos estaduais e municipais. Como o conselho gestor é relativamente novo, ainda não se pode avaliar se elas se reproduzirão nesse caso.

Por fim, algumas palavras sobre a estrutura geral do Conselho Gestor da Reserva da Biosfera do Cinturão Verde da Cidade de São Paulo. Percebe-se que o governo estadual possui cinco votos entre quatorze, mais que um terço, o que lhe confere o papel de decidir de fato os rumos das discussões.

\section{Considerações finais}

A articulação de escalas de gestão é uma das características que definem políticas de salvaguarda de áreas naturais. Em geral, por meio da cooperação internacional se estabelecem possibilidades de intercâmbio científico e técnico em prol da conservação dos ambientes naturais. Quando ela ocorre por meio de um tratado internacional, a cooperação é mais forte por obrigar as partes a cooperarem. Mas quando resulta de ações isoladas de órgãos multilaterais com países tem-se uma cooperação frágil, como se verifica na Reserva da Biosfera do Cinturão Verde da Cidade de São Paulo. 
A UNESCO teve um papel de destaque no início, ao expor procedimentos e ao capacitar pessoal para a gestão da área protegida. Entretanto, poucos anos após a criação da reserva, deixou de repassar recursos e praticamente não anima as ações, que apenas são avaliadas em reuniões de acompanhamento. Por outro lado, é reconhecido pelos técnicos que o rótulo Reserva da Biosfera amplia as possibilidades de captação de recursos para financiar os programas.

Da parte do governo do Estado de São Paulo, a quem cabe gerir a área protegida, destaca-se a ágil definição do Conselho Gestor menos que um mês após a criação do SNUC. Entretanto, ao analisar-se a composição e atribuições de tal comitê, verifica-se que ele está esvaziado de poder político, dado seu caráter consultivo. E, além disso, indica uma maioria do governo do estado, que conta com mais que um terço do total dos votantes.

A sociedade civil, causa primeira que mobilizou o estado para a criação da Reserva da Biosfera do Cinturão Verde da Cidade de São Paulo, restou participar de um conselho consultivo com, no máximo quatro cadeiras, duas de ONGs e duas de membros da comunidade, já que, a depender do perfil dos acadêmicos a ocupar a representação, pode-se esperar uma vinculação aos interesses estaduais.

Por isso, entre as características necessárias à governança listadas nesse artigo nota-se que houve mobilização social, porém restrita à criação da reserva. Como as eleições para representantes da sociedade civil dependem de normas externas ao Conselho Gestor, não se pode garantir que os eleitos tenham legitimidade às causas e fontes de conflitos socioambientais que a delimitação da área protegida engendra. É muito amplo e com pouco significado definir duas cadeiras à comunidade local sem definir o que se entende por isso. Resta saber se a população que vive nela está organizada para fluir suas demandas nesse foro político.

Por fim, o governo estadual criou uma estrutura de gestão que afasta a mobilização social ao definir o Conselho Gestor como consultivo. Não foi criada uma rede de serviços estatais capaz de assimilar a participação social nas decisões.

\section{Notas}

A Região Metropolitana de São Paulo é constituída por 39 municípios, dos quais o principal é São Paulo. Nela vivem, em 2006, cerca de 18 milhões de habitantes, em uma área de cerca de 8051 de km2, dos quais cerca de $1747 \mathrm{~km} 2$ urbanizados (CETESB, 2006). Os municípios da Região Metropolitana são: Arujá, Barueri, Biritiba-Mirim, Cajamar, Caieiras, Carapicuíba, Cotia, Diadema, Embu, Embu-Guaçu, Ferraz de Vasconcelos, Francisco Morato, Franco da Rocha, Guararema, Guarulhos, Itapevi, Itaquaquecetuba, Itapecerica da Serra, Jandira, Juquitiba, Mairiporã, Mauá, Mogi das Cruzes, Osasco, Pirapora do Bom Jesus, Poá, Ribeirão Pires, Rio Grande da Serra, Salesópolis, Santa Isabel, Santana de Parnaíba, Santo André, São Bernardo do Campo, São Caetano do Sul, São Lourenço da Serra, São Paulo, Suzano, Taboão da Serra e Vargem Grande Paulista.

2 Um dos debates mais interessantes em torno do tema da governança ambiental é o papel das Nações Unidas no processo. Esty e Ivanova (2005), discutem em uma perspectiva de reforma do sistema e de seus órgãos internos. Já Elliott (2005), acredita que é preciso ampliar o papel do Conselho de Segurança da ONU, dado o caráter central que as questões ambientais adquiriram. Para uma interpretação da governança do Brasil, ver Ribeiro (2009).

O Instituto Florestal foi criado em 1886 e administra 90 Unidades de Conservação do Estado de São Paulo, o que corresponde a cerca de $853.263,40$ ha (3,47\% da superfície do estado de São Paulo), distribuídos por 114 municípios. Entre as atividades consta o apoio à pesquisa e a iniciativas de educação ambiental.

\section{Agradecimentos}

Trabalho resultado do projeto Exclusion sociale, territoires et politiques urbaines (S.E.T.U.P.): Une comparaison entre l'Inde et le Brésil, financiado pela Agence Nationale de la Recherche, ANR, da França. 


\section{Referência Bibliográfica}

ALTVATER, E. Restructuring the Space of Democracy. Ambiente e Sociedade, No 3 e 4, pp. 5-27, 1999. CAVALCANTI, Clóvis. Economia e ecologia: problemas da governança ambiental no Brasil. Revista Iberoamericana de Economia Ecológica. V. 1. pp. 1-10, 2004.

CETESB. Relatório de Qualidade do Ar no Estado de São Paulo - 2005. São Paulo : CETESB, 2006. COMMISSION ON GLOBAL GOVERNANCE. An overview of Our Global Neighbourhood - The Report of the Commission on Global Governance. Oxford: Oxford University Press, 1995.

ELLIOTT, Lorraine. Expanding the mandate of the United Nations Security Council, IN: CHAMBERS, Bradnee and GREEN, Jessica (Eds.). Reforming international governance. Tokyo : United Nations University Press, 2005, pp. 204-226.

ESTY, Daniel e IVANOVA, Maria. Revitalização da governança ambiental global: um enfoque baseado em funções. IN: ESTY, Daniel e IVANOVA, Maria (Org.). Governança ambiental global. São Paulo : SENAC, 2005.

JACOBI, Pedro. 2003. Espaços públicos e práticas participativas na gestão do meio ambiente no Brasil. Sociedade Estado, vol.18 nº $1 / 2$. Editora UnB, Brasília.

KANEIE, Norichika and HAAS, Peter (Eds.). Emerging forces in environmental governance. Tokyo : United Nations University Press, 2004.

MARTINEZ-ALIER, Joan. O ecologismo dos pobres. São Paulo : Contexto, 2007.

MELLO, Leonel I. A. Quem tem medo da geopolítica? São Paulo : Edusp/HUCITEC, 1999.

O'BRIEN, Robert et. All (Eds.). Contesting global governance: multilateral institutions and global social movements. Cambridge : Cambridge University Press, 2000.

RIBEIRO, Wagner C. A ordem ambiental internacional. São Paulo : Contexto, 2001.

RIBEIRO, Wagner C (Org.). Governança da água no Brasil: uma visão interdisciplinar. São Paulo: Annablume, 2009.

Fontes eletrônicas:

http://www.iflorestal.sp.gov.br/rbcv, acessado em julho de 2008.

http://www.iflorestal.sp.gov.br/rbcv/ar_proteg.asp, acessado em julho de 2008.

Trabalho enviado em maio de 2009

Trabalho aceito em setembro de 2009 